\title{
Uniportal versus multiportal video-assisted thoracoscopic surgery in the treatment of lung cancer: a Canadian single-centre retrospective study
}

\author{
Tarek A. Bin Yameen, MBiotech \\ Vaibhav Gupta, MD \\ Abdollah Behzadi, MD, MBA
}

Presented at the Canadian Association of Thoracic Surgeons annual meeting, Sept. 16, 2017, Victoria, B.C.

Accepted May 6, 2019

\section{Correspondence to:}

A. Behzadi

Carlo Fidani Regional Cancer Centre

Trillium Health Partners

2200 Eglinton Ave W

Mississauga ON L5M 2N1

abdollah.behzadi@thp.ca

DOI: $10.1503 /$ cjs.001418
Background: Observational studies comparing uniportal and multiportal videoassisted thoracoscopic surgery (VATS) in the treatment of lung cancer have produced conflicting results. We present a Canadian study comparing clinical outcomes of uniportal and multiportal VATS in the treatment of lung cancer.

Methods: A retrospective study evaluating patients who underwent multiportal (2012-2014) or uniportal (2014-2016) VATS lobectomies, segmentectomies and wedge resections for lung cancer. Clinical outcomes measured included patient demographics, tumour factors, operative factors, length of hospital stay, postoperative complications, analgesic use, pain scores and mortality. Descriptive statistics were used to compare the 2 groups.

Results: Of 185 patients, 65 underwent uniportal and 63 underwent multiportal VATS resection. Patients were similar in terms of their baseline demographics, comorbidies and cancer characteristics. Median operative time was 184 and $185 \mathrm{~min}$ utes in the uniportal and multiportal groups, respectively. There were 5 conversions to thoracotomy in the uniportal group and 1 in the multiportal group. Similar lymph node retrieval (median 7 v. 5 nodes) and positive margin rates (6.2\% v. $4.8 \%)$ were seen in the 2 groups. Median length of stay was 2 days (interquartile range [IQR] 1-3) and 3 days (IQR 2-4) in the uniportal and multiportal groups, respectively. Rates of postoperative complications were similar in the 2 groups $(16.9 \% \mathrm{v} .19 .0 \%, p=0.76)$. Patient-controlled analgesia use and pain scores did not differ between the groups.

Conclusion: Adoption of uniportal VATS appears to be feasible and safe, without compromising oncologic principles or increasing intraoperative resource utilization. Larger, prospective studies can help confirm these findings.

Contexte : Les études observationnelles qui comparent les interventions chirurgicales par thoracoscopie vidéo-assistée (VATS) uniportale et multiportale dans le traitement du cancer du poumon se contredisent. Notre étude compare les résultats cliniques des 2 types d'interventions en milieu canadien, pour les patients atteints d'un cancer du poumon.

Méthodes : Nous avons rétrospectivement étudié le dossier de patients qui ont subi une lobectomie, une segmentectomie ou une résection cunéiforme périphérique par VATS multiportale (2012-2014) ou uniportale (2014-2016) pour cause de cancer du poumon. Les variables examinées étaient les caractéristiques personnelles des patients, les caractéristiques des tumeurs, les paramètres et détails de l'intervention, la durée d'hospitalisation, les complications postopératoires, l'utilisation d'analgésiques, l'intensité de la douleur ressentie et la mortalité. Nous avons comparé les 2 groupes à l'aide de statistiques descriptives.

Résultats : Sur les 185 patients repérés, 65 avaient subi une VATS uniportale, et 63, une VATS multiportale. Les participants des 2 groupes se ressemblaient sur le plan de leur situation personnelle, de leurs comorbidités et des caractéristiques de leur cancer. La durée médiane de l'intervention était de 184 minutes pour les opérations uniportales et de 185 minutes pour les opérations multiportales. Les chirurgiens sont passés à la thoracotomie lors de 5 interventions uniportales et d'une intervention multiportale. Le nombre médian de nœuds lymphoïdes retirés (7 c. 5) et le taux de marges positives $(6,2 \%$ c. $4,8 \%)$ étaient comparables entre les 2 groupes. La durée médiane d'hospitalisation était de 2 jours dans le groupe d'intervention uniportale et de 3 jours 
dans le groupe d'intervention multiportale (intervalle interquartile $1-3$ et $2-4$, respectivement). Le taux de complications postopératoires était semblable (16,9\% c. 19,0\%; $p=0,74)$, tout comme l'utilisation d'analgésiques contrôlée par le patient et l'intensité de la douleur ressentie.

Conclusion : Il semble que l'adoption de la VATS uniportale soit réaliste et sûre, assurerait le respect des principes oncologiques et n'accrôitrait pas l'utilisation de ressources en contexte opératoire. Il faudra cependant mener des études prospectives de plus grande envergure pour confirmer ces résultats.

$\mathrm{n}$ the past decade, numerous meta-analyses have demonstrated that video-assisted thoracoscopic surgery (VATS) is associated with shorter hospital stays, reduced complication rates and improved long-term survival when compared with open thoracotomy. ${ }^{1-3}$ In recent years, uniportal VATS has emerged as a more minimally invasive approach than the conventional multiportal approach. ${ }^{4-6}$ Several reports have demonstrated its feasibility in the surgical management of mediastinal and lung tumours..$^{6-8}$ As well, early studies suggested that in addition to reducing incisions, uniportal VATS is associated with a significant reduction in postoperative pain ${ }^{9,10}$ and paresthesia $^{11-13}$ and with better patient satisfaction. ${ }^{12,14,15}$

However, recent meta-analyses comparing clinical outcomes of uniportal and multiportal VATS have produced conflicting results. A recent best evidence topic review of 8 observational studies comparing the 2 approaches in minor and major thoracic procedures found no differences in most postoperative outcomes. ${ }^{16}$ In contrast, a systematic review of 8 observational studies comparing the 2 approaches in lobectomies demonstrated a statistically significant but clinically minor reduction in hospital stay, chest tube drainage and overall morbidity for uniportal VATS. ${ }^{17}$ However, this meta-analysis had some notable limitations. ${ }^{17}$ First, some studies excluded cases converted to thoracotomy from the final statistical analysis. Second, initial uniportal VATS cases were excluded from the analysis to account for a learning curve. Furthermore, the reported length of stay $(6.2 \pm 2.6 \mathrm{~d})$ was significantly greater than the reported median length of hospital stay (4 d) in the Society of Thoracic Surgeons' General Thoracic Surgery Database. ${ }^{18}$ Of the 8 studies that were compared in the meta-analysis, 7 originated in Asia, where the observed increase in the length of stay could be attributed to confounding variables, such as sociocultural influences on readiness for early discharge, financial considerations, patient confidence and different discharge protocols. ${ }^{19}$

This report presents the results of a single-centre Canadian study comparing uniportal and multiportal VATS lobectomies, segmentectomies and wedge resections for the treatment of lung cancer. The objective of this study was to assess intraoperative and postoperative outcomes following uniportal and multiportal VATS lung cancer resection. The hypothesis was that uniportal VATS is safe and has similar intra- and post-operative outcomes when compared with multiportal VATS.

\section{Methods}

We performed an observational, retrospective study comparing uniportal and multiportal VATS (lobectomies, segmentectomies and wedge resections) for lung cancer at a tertiary care centre for thoracic surgery in Ontario (Trillium Health Partners, Credit Valley Site). We included consecutive patients with a preoperative or postoperative biopsy-proven primary or secondary lung cancer. Patients undergoing pneumonectomy and those without a cancer diagnosis were excluded. All surgeries were performed between June 2012 and August 2016 by a single surgeon (A.B.). There was a complete change in surgical approach from multiportal to uniportal VATS in September 2014. From June 2012 to August 2014, multiportal VATS procedures were exclusively performed for lung resections and no uniportal VATS procedures were performed (multiportal group). If the multiportal VATS approach was not feasible, conversion to thoracotomy was performed. Between September 2014 and August 2016, all lung resections were attempted by uniportal VATS (uniportal group). During this time period, no multiportal VATS procedures were performed and if the uniportal approach was not feasible, conversion to thoracotomy was completed. The data were retrieved from patient records at the hospital.

\section{Surgical technique}

The operations were completed with the patients under general anesthesia and lung isolation. The conventional multiportal (3-port) VATS procedure was completed as described by Sihoe ${ }^{20}$ and the uniportal VATS approach was completed as described by Gonzalez-Rivas et al. ${ }^{6}$ In multiportal VATS, there is a utility incision in addition to 2 or 3 port sites. Uniportal VATS includes a utility incision only and no other incisions. All surgeries involved bronchoscopy and invasive mediastinal staging intraoperatively. Postoperative analgesia was administered via intravenous patient-controlled anesthesia (PCA) or epidural catheter at the discretion of the treating anesthesiologist. Chest tubes were removed when less than $200 \mathrm{~mL}$ of pleural fluid was drained over the preceding 12 hours, no air leak was observed on forced expiration and the same-day chest $\mathrm{x}$-ray image was satisfactory. 
Patients were discharged when they were ambulating unassisted, their pain was controlled on oral analgesics and no active treatment was required. Finally, patients were discharged on Heimlich valves if they met the discharge requirements but required continuing chest tube drainage for persistent air leak.

\section{Data collection}

Institutional approval was obtained from the Trillium Health Partners' Research Ethics Board. Charts of patients who underwent uniportal or multiportal VATS between June 2012 and August 2016 were reviewed. Preoperative variables collected included age; sex; body mass index; pulmonary function; comorbidities; smoking history; tumour pathology, size, location and staging; and operative procedure performed. Intraoperative variables included duration of operation, decortications required, cartridge use, conversion to thoracotomy, lymph nodes retrieved and involved, positive margins, blood transfusions required and blood loss. Postoperative variables included length of hospital stay, duration of chest tube, complications, admission to critical care, reinterventions, 24-hour dose and total days' duration of PCA use, 24-hour visual analogue score, and inpatient and 90 -day mortality.

\section{Statistical analysis}

The SPSS software package 24.0 for Windows (SPSS Inc.) was used for statistical analysis. Continuous variables were assessed for normality with the D'Agostino-Pearson test. Normally distributed variables are presented as means with standard deviation (SD) and non-normally distributed variables as medians with interquartile range (IQR). Categorical variables are presented as percentages. Continuous variables were analyzed using the Student $t$ test and the Levene test for equality of variances for means and with the Mood median test and the Yates continuity correction for medians. Categorical variables were analyzed using the Fisher exact test or the $\chi^{2}$ test. The significance level was set at $p<0.05$.

\section{REsults}

A total of 185 patients underwent VATS pulmonary procedures during the study period (Fig. 1). After 57 patients who did not meet the inclusion criteria were excluded, 128 patients were available for analysis in the uniportal group (65 patients) and the multiportal group (63 patients).

Patient characteristics are presented in Table 1 . There were no significant differences in age, sex, body mass index, pulmonary function tests, smoking status or history between the groups. In terms of comorbidities, there was a borderline significant difference $(p=0.04)$ in chronic obstructive pulmonary disease diagnosis between the uniportal (21 patients, $32.3 \%$ and multiportal (10 patients, $15.9 \%)$ groups. There were no significant differences in tumour characteristics or type of resection performed between the groups.

The perioperative outcomes are presented in Table 2 . There were no significant differences in operative time,

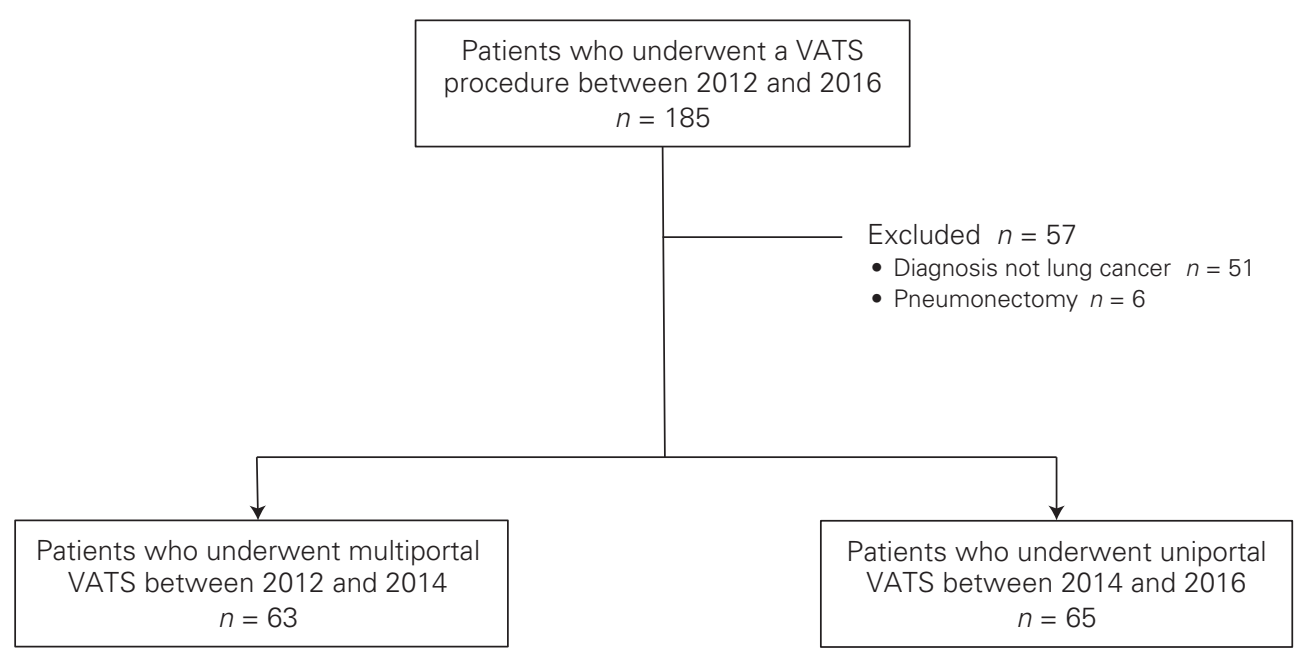

Fig. 1. Patients included in the study. VATS = video-assisted thoracoscopic surgery. 
number of stapler cartridges used, decortication required or conversions to thoracotomy. Conversions in the uniportal group (5 patients, $7.7 \%$ ) were due to difficult dissections

\begin{tabular}{|c|c|c|c|}
\hline \multirow[b]{2}{*}{ Characteristic } & \multicolumn{2}{|c|}{ No. $(\%)$ of patients* } & \multirow[b]{2}{*}{$p$ value } \\
\hline & $\begin{array}{c}\text { Uniportal } \\
\text { VATS } \\
n=65\end{array}$ & $\begin{array}{c}\text { Multiportal } \\
\text { VATS } \\
n=63\end{array}$ & \\
\hline Age, $y r$, mean $\pm S D$ & $67.6 \pm 8.9$ & $69.2 \pm 7.9$ & 0.28 \\
\hline Male sex & $32(49)$ & $21(33)$ & 0.08 \\
\hline $\mathrm{BMI}$, mean $\pm \mathrm{SD}$ & $29.0 \pm 7.8$ & $27.0 \pm 4.5$ & 0.10 \\
\hline $\mathrm{FEV}_{1}, \mathrm{~L}$, mean $\pm \mathrm{SD}$ & $2.0 \pm 0.6$ & $2.0 \pm 0.6$ & 0.74 \\
\hline $\begin{array}{l}\mathrm{FEV}_{1}, \% \text { predicted, } \\
\text { mean } \pm \mathrm{SD}\end{array}$ & $84.2 \pm 21.9$ & $87.3 \pm 19.9$ & 0.43 \\
\hline $\begin{array}{l}\mathrm{DLCO}, \% \text { predicted, } \\
\text { mean } \pm \text { SD }\end{array}$ & $65.6 \pm 20.0$ & $65.8 \pm 19.0$ & 0.95 \\
\hline Current smoker & $13(20.0)$ & $16(25.4)$ & 0.77 \\
\hline Smoking history & $53(81.5)$ & $48(76.1)$ & 0.52 \\
\hline $\begin{array}{l}\text { Average pack years, } \\
\text { mean } \pm \text { SD }\end{array}$ & $32.2( \pm 16.5)$ & $37.9(17.0)$ & 0.10 \\
\hline \multicolumn{4}{|l|}{ Comorbidities } \\
\hline Hypertension & $39(60.0)$ & $40(63.5)$ & 0.72 \\
\hline COPD & $21(32.3)$ & $10(15.9)$ & 0.04 \\
\hline Diabetes mellitus & $18(27.7)$ & $11(17.5)$ & 0.21 \\
\hline Dyslipidemia & $14(21.5)$ & $7(11.1)$ & 0.15 \\
\hline Hypercholesterolemia & $13(20.0)$ & $6(9.5)$ & 0.14 \\
\hline Coronary artery disease & $11(16.9)$ & $5(7.9)$ & 0.18 \\
\hline Previous stroke & $3(4.6)$ & $5(7.9)$ & 0.49 \\
\hline Histologic type & & & 0.27 \\
\hline Adenocarcinoma & $48(73.8)$ & $36(57.1)$ & \\
\hline Metastatic tumour & $5(7.7)$ & $6(9.5)$ & \\
\hline Squamous cell carcinoma & $5(7.7)$ & $8(12.7)$ & \\
\hline Neuroendocrine tumour & $3(4.6)$ & $2(3.2)$ & \\
\hline Carcinoid tumour & $2(3.1)$ & $3(4.8)$ & \\
\hline Other & $3(4.6)$ & $5(7.9)$ & \\
\hline $\begin{array}{l}\text { Tumour size, } \mathrm{cm}, \\
\text { mean } \pm \text { SD }\end{array}$ & $2.7 \pm 1.5$ & $2.8 \pm 1.7$ & 0.86 \\
\hline Tumour location & & & 0.11 \\
\hline Left upper lobe & $13(20.0)$ & $25(39.7)$ & \\
\hline Left lower lobe & $16(24.6)$ & $7(11.1)$ & \\
\hline Right upper lobe & $14(21.5)$ & $11(17.5)$ & \\
\hline Right middle lobe & $8(12.3)$ & $6(9.5)$ & \\
\hline Right lower lobe & $14(21.5)$ & $13(20.6)$ & \\
\hline Cancer stage & & & 0.70 \\
\hline 0 & $1(1.5)$ & 0 & \\
\hline IA & $21(32.3)$ & $19(30.2)$ & \\
\hline IB & 25 (38.5) & $19(30.2)$ & \\
\hline$\| \mathrm{A}$ & $3(4.6)$ & $4(6.3)$ & \\
\hline IIB & $3(4.6)$ & $2(3.2)$ & \\
\hline IIIA & $7(10.8)$ & $8(12.7)$ & \\
\hline Operative procedure & & & 0.71 \\
\hline Lobectomy & $43(58.9)$ & $40(57.1)$ & \\
\hline Segmentectomy & $20(27.4)$ & $17(24.3)$ & \\
\hline Wedge resection & $10(13.7)$ & $13(18.6)$ & \\
\hline \multicolumn{4}{|c|}{$\begin{array}{l}\mathrm{BMI}=\text { body mass index; } \mathrm{COPD}=\text { chronic obstructive pulmonary disease; } \mathrm{DLCO}= \\
\text { diffusing capacity of the lungs for carbon monoxide; } \mathrm{FEV},=\text { forced expiratory volume in } 1 \\
\text { second; } \mathrm{SD}=\text { standard deviation; VATS = video-assisted thoracoscopic surgery. } \\
\text { *Unless indicated otherwise. }\end{array}$} \\
\hline
\end{tabular}

(adhesions or tumour location); there was 1 conversion in the multiportal group (1.6\%), which was due to a bleed from an incomplete vascular staple line. The groups were similar in terms of median number of lymph nodes retrieved and involved, positive margins, blood transfusions required and blood loss. No conversion from uniportal to multiportal VATS was performed.

The postoperative outcomes are shown in Table 3. There was a 1-day reduction in median length of stay in the uniportal group compared with the multiportal group: the median length of stay was 2 (IQR 1-3) days in the uniportal and 3 (IQR 2-4) days in the multiportal group $(p=0.01)$. There was a similar reduction in chest tube duration: 2 (IQR 2-3) days in the uniportal group and 3 (IQR 2-9) days in the multiportal group $(p=0.01$ ). Similarly, only 6 patients $(9.2 \%)$ in the uniportal group had an air leak for longer than 3 days, compared with 18 patients $(28.6 \%)$ in the multiportal group. As well, fewer patients were discharged home with a Heimlich valve in the uniportal group than in the multiportal group $(9.2 \%$ v. $28.6 \%, p=0.01)$. Most notably, there were similar rates of complications in the uniportal group (11 patients, 16.9\%) and the multiportal group (12 patients, $19.0 \%)(p=0.76)$.

No significant differences were found in terms of admission to critical care ( $p=0.73$; Table 3$)$ or further procedures required ( $p=0.10$; Table 3$)$. Four patients $(6.2 \%)$ in the uniportal group were admitted to critical care: 1 for acute respiratory failure, 1 for atrial fibrillation, 1 for postoperative bleeding and 1 for subcutaneous emphysema. Three patients $(4.8 \%)$ in the multiportal group were admitted to critical care: 2 for acute respiratory failure and 1 for postoperative delirium. Repeat procedures were performed for 5 patients

\begin{tabular}{|c|c|c|c|}
\hline \multirow[b]{2}{*}{ Outcome } & \multicolumn{2}{|c|}{ No. $(\%)$ of patients* } & \multirow[b]{2}{*}{$p$ value } \\
\hline & $\begin{array}{c}\text { Uniportal } \\
\text { VATS } \\
n=65\end{array}$ & $\begin{array}{c}\text { Multiportal } \\
\text { VATS } \\
n=63\end{array}$ & \\
\hline $\begin{array}{l}\text { Duration of operation, min, } \\
\text { median (IQR) }\end{array}$ & $184(144-241)$ & $185(138-227)$ & 0.86 \\
\hline $\begin{array}{l}\text { No. of cartridges, median } \\
\text { (IQR) }\end{array}$ & $8(6-11)$ & $8(6-12)$ & 0.63 \\
\hline Decortication required & $9(13.8)$ & $11(17.5)$ & 0.63 \\
\hline Conversion to thoracotomy & $5(7.7)$ & $1(1.6)$ & 0.21 \\
\hline $\begin{array}{l}\text { No. of lymph nodes retrieved, } \\
\text { median (IQR) }\end{array}$ & $7(3-10)$ & $5(3-9)$ & 0.11 \\
\hline $\begin{array}{l}\text { No. of lymph nodes involved, } \\
\text { median (IQR) }\end{array}$ & $2(1-4)$ & $2(1-5)$ & 0.39 \\
\hline Positive margins & $4(6.2)$ & $3(4.8)$ & 0.35 \\
\hline Blood transfusion required & $3(4.6)$ & $1(1.6)$ & 0.49 \\
\hline Blood loss, $\mathrm{mL}$ & $100(100-300)$ & $100(100-300)$ & 0.86 \\
\hline
\end{tabular}


(7.7\%) in the uniportal group: 2 for persistent air leak, 1 for bronchopleural fistula closure, 1 for postoperative bleeding and 1 for hematoma evacuation. A repeat procedure was required for 1 patient $(1.6 \%)$ in the multiportal group for mucous plug removal. One patient in the multiportal group died in the hospital because of respiratory failure, and 1 patient in the uniportal group died within 90 days after the operation because of distant metastasis.

Table 4 shows postoperative pain outcomes. There was a significant difference in the number of patients who received PCA in the uniportal and multiportal groups $(84.6 \%$ v. $68.3 \%, p=0.03)$. There were no significant differences found in 24-hour PCA use, visual analogue score, or duration of PCA use.

\begin{tabular}{|c|c|c|c|}
\hline \multirow[b]{2}{*}{ Outcome } & \multicolumn{2}{|c|}{ No. (\%) of patients* } & \multirow[b]{2}{*}{$p$ value } \\
\hline & $\begin{array}{c}\text { Uniportal } \\
\text { VATS } \\
n=65\end{array}$ & $\begin{array}{c}\text { Multiportal } \\
\text { VATS } \\
n=63\end{array}$ & \\
\hline $\begin{array}{l}\text { Length of stay, d, } \\
\text { median (IQR) }\end{array}$ & $2(1-3)$ & $3(2-4)$ & 0.01 \\
\hline $\begin{array}{l}\text { Chest tube duration, } d \text {, } \\
\text { median (IQR) }\end{array}$ & $2(2-3)$ & $3(2-9)$ & 0.01 \\
\hline $\begin{array}{l}\text { Discharge home with } \\
\text { Heimlich valve }\end{array}$ & $6(9.2)$ & $18(28.6)$ & 0.01 \\
\hline Admission to critical care & $4(6.2)$ & $3(4.8)$ & 0.73 \\
\hline Further procedure required & $5(7.7)$ & $1(1.6)$ & 0.10 \\
\hline Complications & $11(16.9)$ & $12(19.0)$ & 0.76 \\
\hline ICU delirium & $1(1.5)$ & $3(4.8)$ & \\
\hline Arrhythmia & $2(3.1)$ & $2(3.2)$ & \\
\hline $\begin{array}{l}\text { Respiratory } \\
\text { complication }\end{array}$ & $4(6.2)$ & $4(6.3)$ & \\
\hline Renal complication & $2(3.1)$ & $1(1.6)$ & \\
\hline $\begin{array}{l}\text { Postoperative } \\
\text { bleeding/hematoma }\end{array}$ & $2(3.1)$ & 0 & \\
\hline Deep vein thrombosis & 0 & $1(1.6)$ & \\
\hline Transient ischemic attack & 0 & $1(1.6)$ & \\
\hline In-hospital mortality & $0(0)$ & $1(1.6)$ & - \\
\hline 90-day mortality & $1(1.5)$ & $0(0)$ & - \\
\hline \multicolumn{4}{|c|}{$\begin{array}{l}\text { ICU = intensive care unit; IQR = interquartile range; VATS = video-assisted thoracoscopic } \\
\text { surgery. } \\
\text { *Unless indicated otherwise. }\end{array}$} \\
\hline
\end{tabular}

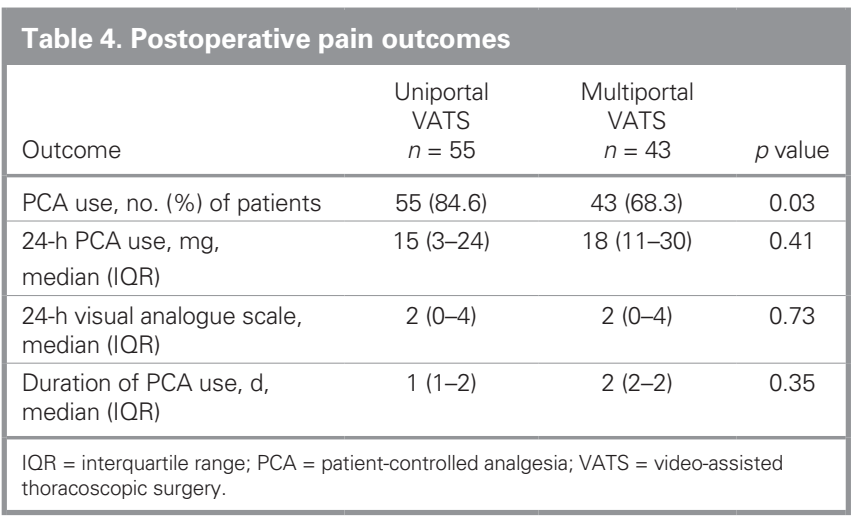

\section{Discussion}

Despite the presumed advantages of single-incision over multi-incision VATS lung resection, there is a paucity of supportive data in the literature. This study compared the 2 approaches performed by a single surgeon at a highvolume thoracic surgery centre in Canada, where a complete change in practice occurred from multiportal to uniportal VATS during the study period. This is one of the earliest and largest Canadian series comparing uniportal and multiportal VATS lobectomies, segmentectomies and wedge resections in the treatment of lung cancer.

Patients in the 2 groups were comparable. We found that operative duration, blood loss, lymph node yield and resection margin rates were similar in the 2 groups. The finding of similar operative time is consistent with recent studies that found no differences in mean length of operation time between the 2 approaches in lobectomies. ${ }^{21-27}$ Likewise, no differences were evident in the number of stapler cartridges used. This appears to demonstrate that uniportal VATS does not increase intraoperative resource utilization compared with the traditional multiportal VATS approach.

The similarities in positive margin, blood transfusion and postoperative complication rates suggest that uniportal VATS does not appear to compromise patient safety and oncologic treatment principles. The slightly higher conversion rate to open thoracotomy in the uniportal group $(7.7 \%$ v. $1.6 \%)$ is probably because of the surgeon's learning curve as uniportal VATS was introduced. These results corroborate recent findings that demonstrated no differences in rates of conversions to thoracotomies or mean operative blood loss between the 2 approaches in lobectomies. ${ }^{17,21-27} \mathrm{We}$ note that our practice was to convert to open thoracotomy rather than multiportal VATS when the uniportal approach was not feasible. We may have erred on the side of caution earlier in the learning experience, and it may be reasonable to make an attempt at multiportal VATS before performing thoracotomy.

There was a 1-day reduction in chest tube duration and hospital length of stay for patients in the uniportal VATS group compared with the multiportal VATS group (median 2 v. 3 d). It is unclear whether this was driven by surgical technique, a trend toward shorter hospital stays over time, or other factors. A 2016 meta-analysis suggested that uniportal surgery decreases resource utilization through reductions in length of stay and chest tube duration. ${ }^{17}$ Although our study corroborates that finding, a Canadian series reported by French and colleagues found that both uniportal (50 patients) and multiportal (50 patients) groups had a median stay of 4 days. ${ }^{28}$ In a series reported by Drevet and Figueroa in Quebec (250 patients), the median stay was 3 days. ${ }^{29}$ Our discharge protocol allowed for patients to be sent home with Heimlich valves if they met discharge requirements, which may explain the shorter length of stay 
in our series. Given that the patients in the multiportal group were treated earlier in the study period, we believe the lower rate of air leak beyond 3 days, and thus shorter chest tube duration and hospital stay, in the uniportal group could be a result of residual confounding from improved surgeon experience. Therefore, the appropriate inference to draw may be that uniportal VATS appears to be safe and feasible and at least does not contribute to a higher risk of air leak when performed by surgeons who safely perform multiportal VATS.

The similar rates of complications in the 2 groups demonstrate the safety profile of uniportal VATS. The metaanalysis alluded to earlier also found very similar complication rates in the uniportal and multiportal groups $(12.0 \%$ v. $13.7 \%) .{ }^{17} \mathrm{We}$ did not find any trend toward a complication being more common in 1 group than in the other, probably because of the low number of complications overall. Similarly, mortality was equivalent in the 2 groups. These findings provide reassurance that a uniportal technique can be implemented safely in a high-volume community thoracic surgery practice.

There is debate about whether uniportal surgery reduces pain compared with traditional VATS resection. The existing data are conflicting; overall they suggest there is no difference in pain score. ${ }^{9,10,17,19}$ In our study, although PCA use was greater in the more contemporary uniportal group, as expected, there were no differences in 24-hour median PCA use, pain scores or duration of PCA use. If the literature continues to show equivalent surgical outcomes between uniportal and multiportal surgery, then patient-reported outcomes such as pain scores may help clinicians to favour 1 strategy over the other. This would be an ideal question for a future randomized trial powered to detect a difference in patient-reported postoperative pain scores.

\section{Limitations}

This study has limitations. Although there was no bias driven by surgeon selection into the uniportal or multiportal groups, the multiportal group was a historical control. The trend toward improvement in general medical and surgical care over time may favour the uniportal group, and the reduced chest tube duration or length of stay could reflect this. Second, the uniportal group included the surgeon's learning curve with this new technique; this could account for the fact that there were more conversions in the uniportal group. Furthermore, the determination of complications was dependent on clinician adjudication, which could be a source of bias. The collection of comorbidity data was opportunistic through clinical care and not standardized through a system such as the Charlson Comorbidity Index, and so we may have underestimated the true burden of multicomorbidity. Another limitation of this study is its sample size.
Although to our knowledge this is the largest Canadian series comparing uniportal and multiportal VATS, statistical testing was probably underpowered where differences were not found, and a larger study would be needed to conclude whether there is truly no difference in outcome between these 2 groups. Finally, this is a report of a single surgeon's experience and may not be generalizable to all surgeons, but our study has the advantage of controlling for some surgeon-specific confounders, such as practice patterns and style.

\section{Conclusion}

This large Canadian series comparing uniportal and multiportal VATS resections for the treatment of lung cancer shows similar intraoperative resource utilization and perioperative outcomes in the uniportal and multiportal groups when uniportal VATS is adopted by a high-volume surgeon who safely performs multiportal VATS. This study demonstrates the safety and feasibility of performing uniportal VATS in a high-volume community thoracic surgery practice. Larger multicentre, prospective, blinded studies are required to corroborate our findings.

Affiliations: From the Faculty of Medicine, University of Toronto, Toronto, Ont. (Bin Yameen, Gupta, Behzadi); the Division of Thoracic Surgery, Department of Surgery, Trillium Health Partners, University of Toronto, Toronto, Ont. (Gupta, Behzadi); and the Institute of Health Policy, Management and Evaluation, Dalla Lana School of Public Health, University of Toronto, Toronto, Ont. (Gupta).

Competing interests: None declared.

Contributors: T. Bin Yameen and A. Behzadi designed the study. T. Bin Yameen acquired the data, which all authors analyzed. T. Bin Yameen and V. Gupta wrote the article, which all authors reviewed and approved for publication.

\section{References}

1. Cao C, Manganas C, Ang SC, et al. Video-assisted thoracic surgery versus open thoracotomy for non-small cell lung cancer: a metaanalysis of propensity score-matched patients. Interact Cardiovasc Thorac Surg 2013;16:244-9.

2. Yan TD, Black D, Bannon PG, et al. Systematic review and metaanalysis of randomized and nonrandomized trials on safety and efficacy of video-assisted thoracic surgery lobectomy for early-stage non-small-cell lung cancer. 7 Clin Oncol 2009;27:2553-62.

3. Cao C, Gupta S, Chandrakumar D, et al. Meta-analysis of intentional sublobar resections versus lobectomy for early stage non-small cell lung cancer. Ann Cardiothorac Surg 2014;3:134-41.

4. Gonzalez-Rivas D, Paradela M, Garcia J, et al. Single-port videoassisted thoracoscopic lobectomy. Interact Cardiovasc Thorac 2011;12: 514-5.

5. Gonzalez-Rivas D, Paradela M, Fieira E, et al. Single- incision videoassisted thoracoscopic lobectomy: initial results. 7 Thorac Cardiovasc Surg 2012;143:745-7.

6. Gonzalez-Rivas D, Paradela M, Fernandez R, et al. Uniportal videoassisted thoracoscopic lobectomy: two years of experience. Ann Thorac Surg 2013;95:426-32.

7. Gonzalez-Rivas D, Fieira E, Delgado M, et al. Is uniportal thoracoscopic surgery a feasible approach for advanced stages of non-small cell lung cancer? 7 Thorac Dis 2014;6:641-8. 
8. Lin $\mathrm{Z}, \mathrm{Xi} \mathrm{J}, \mathrm{Xu} \mathrm{S}$, et al. Uniportal video-assisted thoracic surgery lobectomy in semiprone position: primary experience of 105 cases. $\mathcal{F}$ Thorac Dis 2015;7:2389-95.

9. Tamura M, Shimizu Y, Hashizume Y. Pain following thoracoscopic surgery: retrospective analysis between single-incision and three-port video-assisted thoracoscopic surgery. 7 Cardiothorac Surg 2013;8:153.

10. Mier JM, Chavarin A, Izquierdo-Vidal C, et al. A prospective study comparing three-port video-assisted thoracoscopy with the single-incision laparoscopic surgery (SILS) port and instruments for the video thoracoscopic approach: a pilot study. Surg Endosc 2013;27:2557-60.

11. Kang do K, Min HK, Jun HJ, et al. Early outcomes of single-port video-assisted thoracic surgery for primary spontaneous pneumothorax. Korean 7 Thorac Cardiovasc Surg 2014;47:384-8.

12. Yang HC, Cho S, Jheon S. Single-incision thoracoscopic surgery for primary spontaneous pneumothorax using the SILS port compared with conventional three-port surgery. Surg Endosc 2013;27:139-45.

13. Salati M, Brunelli A, Xiumè F, et al. Uniportal video-assisted thoracic surgery for primary spontaneous pneumothorax: clinical and economic analysis in comparison to the traditional approach. Interact Cardiovasc Thorac Surg 2008;7:63-6.

14. Ocakcioglu I, Alpay L, Demir M, et al. Is single port enough in minimally surgery for pneumothorax? Surg Endosc 2016;30:59-64.

15. Chen PR, Chen CK, Lin YS, et al. Single-incision thoracoscopic surgery for primary spontaneous pneumothorax. 7 Cardiothorac Surg 2011;6:58.

16. Akter F, Routledge T, Toufektzian L, et al. In minor and major thoracic procedures is uniport superior to multiport video-assisted thoracoscopic surgery? Interact Cardiovasc Thorac 2015;20:550-5.

17. Harris CG, James RS, Tian DH, et al. Systematic review and metaanalysis of uniportal versus multiportal video-assisted thoracoscopic lobectomy for lung cancer. Ann Cardiothorac Surg 2016;5:76-84.

18. Seder C, Wright C, Chang A, et al. The Society of Thoracic Surgeons General Thoracic Surgery Database update on outcomes and quality. Ann Thorac Surg 2016;101:1646-54.

19. Sihoe ADL. Reasons not to perform uniportal VATS lobectomy. 7 Thorac Dis 2016;8:S333-43.
20. Sihoe ADL. The evolution of minimally invasive thoracic surgery: implications for the practice of uniportal thoracoscopic surgery. 7 Thorac Dis 2014;6:S604-17.

21. Chung JH, Choi YS, Cho JH, et al. Uniportal video-assisted thoracoscopic lobectomy: An alternative to conventional thoracoscopic lobectomy in lung cancer surgery? Interact Cardiovasc Thorac 2015; 20:813-9.

22. Hirai K, Takeuchi S, Usuda J. Single-incision thoracoscopic surgery and conventional video-assisted thoracoscopic surgery: a retrospective comparative study of perioperative clinical outcomes. Eur 7 Cardiothorac Surg 2016;49:i37-41.

23. Li C, Ma H, He J, et al. Clinical analysis of thoracoscopic lobectomy in the treatment of peripheral lung cancer with single utility port. Zhongguo Fei Ai Za Zbi 2013;16:487-91.

24. Liu CC, Shih CS, Pennarun N, et al. Transition from a multiport technique to a single-port technique for lung cancer surgery: Is lymph node dissection inferior using the single-port technique? Eur 7 Cardiothorac Surg 2016;49:164-72.

25. Mu JW, Gao SG, Xue Q, et al. A matched comparison study of uniportal versus triportal thoracoscopic lobectomy and sublobectomy for early-stage nonsmall cell lung cancer. Chin Med f (Engl) 2015; 128:2731-5.

26. Shen Y, Wang H, Feng M, et al. Single- versus multiple-port thoracoscopic lobectomy for lung cancer: a propensity-matched study. Eur 7 Cardiothorac Surg 2016;49:148-53.

27. Wang BY, Liu CY, Hsu PK, et al. Single-incision versus multipleincision thoracoscopic lobectomy and segmentectomy: a propensitymatched analysis. Ann Surg 2015;261:793-9.

28. French DG, Thompson C, Gilbert S. Transition from multiple port to single port video-assisted thorascopic anatomic pulmonary resection: early experience and comparison of perioperative outcomes. Ann Cardiothorac Surg 2016;5:92-9.

29. Drevet G, Figuerora PG. Uniportal video-assisted thoracoscopic surgery: safety, efficacy and learning curve during the first 250 cases in Quebec, Canada. Ann Cardiothorac Surg 2016;5:100-6. 